OPEN ACCESS

Edited by:

George Mattheolabakis,

University of Louisiana at Monroe,

United States

Reviewed by:

Chia-Che Chang,

National Chung Hsing University,

Taiwan

Saartjie Roux

Nelson Mandela University,

South Africa

*Correspondence:

Xiao-Feng $L$

linucmed@hotmail.com

Specialty section:

This article was submitted to Pharmacology of Anti-Cancer Drugs,

a section of the journal

Frontiers in Oncology

Received: 26 April 2021

Accepted: 09 July 2021

Published: 29 July 2021

Citation:

Li Y, Zhao L and Li X-F (2021)

Targeting Hypoxia: Hypoxia-Activated

Prodrugs in Cancer Therapy.

Front. Oncol. 11:700407.

doi: 10.3389/fonc.2021.700407

\section{Targeting Hypoxia: Hypoxia-Activated Prodrugs in Cancer Therapy}

\author{
Yue $\mathrm{Li}^{1,2,3}$, Long Zhao ${ }^{1,3}$ and Xiao-Feng $\mathrm{Li}^{1,3^{*}}$ \\ 1 Department of Nuclear Medicine, The Second Clinical Medical College, Jinan University (Shenzhen People's Hospital), \\ Shenzhen, China, 2 The First Affiliated Hospital, Jinan University, Guangzhou, China, ${ }^{3}$ Department of Nuclear Medicine, \\ The First Affiliated Hospital of Southern University of Science and Technology, Shenzhen, China
}

Hypoxia is an important characteristic of most solid malignancies, and is closely related to tumor prognosis and therapeutic resistance. Hypoxia is one of the most important factors associated with resistance to conventional radiotherapy and chemotherapy. Therapies targeting tumor hypoxia have attracted considerable attention. Hypoxia-activated prodrugs (HAPs) are bioreductive drugs that are selectively activated under hypoxic conditions and that can accurately target the hypoxic regions of solid tumors. Both singleagent and combined use with other drugs have shown promising antitumor effects. In this review, we discuss the mechanism of action and the current preclinical and clinical progress of several of the most widely used HAPs, summarize their existing problems and shortcomings, and discuss future research prospects.

Keywords: hypoxia, hypoxia-activated prodrugs, tirapazamine, AQ4N, PR-104, EO9, TH-302, SN30000

\section{INTRODUCTION}

Hypoxia is a hallmark of a wide variety of solid tumors. In tumors, hypoxia arises due to a mismatch between oxygen delivery and consumption. Hypoxia is closely related to tumor progression, metastasis, therapeutic resistance, and poor prognosis (1). Hypoxia in tumor microenvironment leads to the transcriptional induction of a series of genes. The most important factor mediating this response is the hypoxia-inducible factor-1 (HIF-1), which extensively participates in glucose metabolism, angiogenesis, apoptosis, tumor metastasis and therapeutic resistance (2). Under hypoxic condition, HIF-1 $\alpha$ regulates the switch from oxidative phosphorylation to anaerobic glycolysis, by activating the expression of glucose transporter 1 and 3 (GLUT-1 and GLUT-3) and related glycolytic enzymes (3). By regulating its downstream angiogenesis related genes, such as vascular endothelial growth factor (VEGF), basic fibroblast growth factor (bFGF), matrix metalloproteinases (MMPs), HIF-1 $\alpha$ is widely involved in every step of angiogenesis, including endothelial progenitor cells recruitment and their differentiation to endothelial cells and smooth muscle cells, degradation of extracellular matrix, and the stability of peripheral cells (4). HIF-1 $\alpha$ could induce apoptosis by regulating p53, Bcl-2, BNIP-3 and other genes (5). Through induction of MMPs, E-cadherin, CXCR4, CA9, HIF could promote tumor invasion and metastasis by regulating epithelial-to-mesenchymal transition (EMT) (6).

Tumor cells response to hypoxia depends in part on the duration of exposure. Hypoxic tumor cells may undergo necrosis, but some of the tumor cells may adjust to hypoxic stress and survive, which is also mediated by HIF- $1 \alpha$, resulting in a more aggressive phenotype and therapeutic resistance (5). Hypoxia and HIF could induce cell cycle arrest and hypoxic tumor cells generally 
have a relatively low proliferation rate $(7,8)$, while radiotherapy or chemotherapy mainly act on proliferating cells (9-11). Therefore, the hypoxic regions of tumors are usually insensitive to current radiotherapy and chemotherapy, and treatments targeting the hypoxic regions may provide additional clinical benefits. To this end, increasing efforts have been focused on the development of agents that selectively target and kill hypoxic tumor cells.

Hypoxia-activated prodrugs (HAPs), also referred to as bioreductive drugs, are compounds that can be selectively reduced by specific reductases under hypoxic conditions to form cytotoxic agents that precisely target hypoxic tumor cells and have little toxicity to normal tissue. At present, several classes of HAPs have been developed, including quinones, nitroaromatics, aliphatic $\mathrm{N}$-oxides and hetero-aromatic $\mathrm{N}$-oxides. The most representative ones are tirapazamine, AQ4N (banoxantrone), PR-104, EO9 (apaziquone), TH-302 (evofosfamide), and SN30000 (Figure 1). This review puts a special emphasis on the past achievements as well as limitations of HAPs and attempts to analyze the potential reasons for unsuccessful clinical trials, with the aim of guiding future investigations into optimizing the use of this therapeutic approach.

\section{TIRAPAZAMINE}

Tirapazamine (SR-4233, WIN 59075) [3-amino-1,2,4-benzotriazine1,4 dioxide], the first hypoxia-activated prodrug, was reported in 1986 (12). Through one-electron reduction, the prodrug can generate an oxidative radical, which will diffuse into hypoxic regions and cause oxidative damage (13) (Figure 2). Cytochrome P-450 (CYP) is the main catalytic reductase involved in the reduction of tirapazamine (14). Although evidence showed that tirapazamine is a substrate for
$\mathrm{NAD}(\mathrm{P}) \mathrm{H}$ : (quinone acceptor) oxidoreductase (DT-diaphorase) (15), the amount of DT-diaphorase expression in cells did not affect their sensitivity to tirapazamine (16).

Tirapazamine kills hypoxic cells by inducing chromosome aberrations and DNA double-strand breaks (17). Chromosome breaks caused by tirapazamine were more damaging and difficult to repair (18). Under hypoxic conditions, tirapazamine causes damage to both purine and pyrimidine residues in double-stranded DNA. DNA base damage was dominated by formation of formamidopyrimidine and 5-hydroxy-6-hydropyrimidine (19, 20). The DNA damaging activity of tirapazamine mainly results from radicals generated within the nucleus but not in the cytoplasm (21). Tirapazamine can induce acute changes in energy metabolism and intracellular $\mathrm{pH}$ in tumors (22). Skarsgard et al. (23) found that tirapazamine-induced DNA damage was $\mathrm{pH}$-dependent (more effective at acidic $\mathrm{pH}$ ) and could be repaired by certain gene products including uvrC and exonuclease III (24). The affinity of tirapazamine for hypoxic tissues was confirmed by many researchers but Durand and Olive demonstrated that this selectivity of tirapazamine was much lower in vivo (3 fold higher than aerobic) than that observed in vitro (50-500 fold) (25). Under aerobic conditions, tirapazamine can still induce cell cycle interruption and apoptosis, which may lead to its aerobic toxicity (26).

In preclinical studies, tirapazamine effectively inhibited tumor colony-forming in vitro, especially in hypoxic cells (27). Tirapazamine induced cell cycle arrest and apoptosis, and downregulated HIF-1 $\alpha$, CA-IX and VEGF expression $(28,29)$. Brown (30) suggested that the activity of tirapazamine was p53independent, but Yang's study on neuroblastoma revealed that tirapazamine had clinical activity only in p53-functional neuroblastoma (31). Zeman and Brown published a series of reports focusing on the radiosensitization effects of tirapazamine. They reported that tirapazamine enhanced radiation-induced<smiles>Nc1n[n+]([O-])c2ccccc2[n+]1[O-]</smiles>

Tirapazamine<smiles>Cn1c(/C=C/CO)c(CO)c2c1C(=O)C=C(N1CC1)C2=O</smiles>

EO9 (Apaziquone)<smiles>CCCCCNc1ccc(NCC[N+](C)(C)O)c2c1C(=O)c1c(O)ccc(O)c1C2=O</smiles><smiles>Cn1c(COP(=O)(NCCBr)NCCBr)cnc1[N+](=O)[O-]</smiles>

TH-302 (Evofosfamide)<smiles></smiles>

PR-104<smiles>[O-][n+]1nc(CCCN2CCOCC2)[n+]([O-])c2cc3c(cc21)CCC3</smiles>

SN30000

FIGURE 1 | Chemical structures of representative HAPs. 


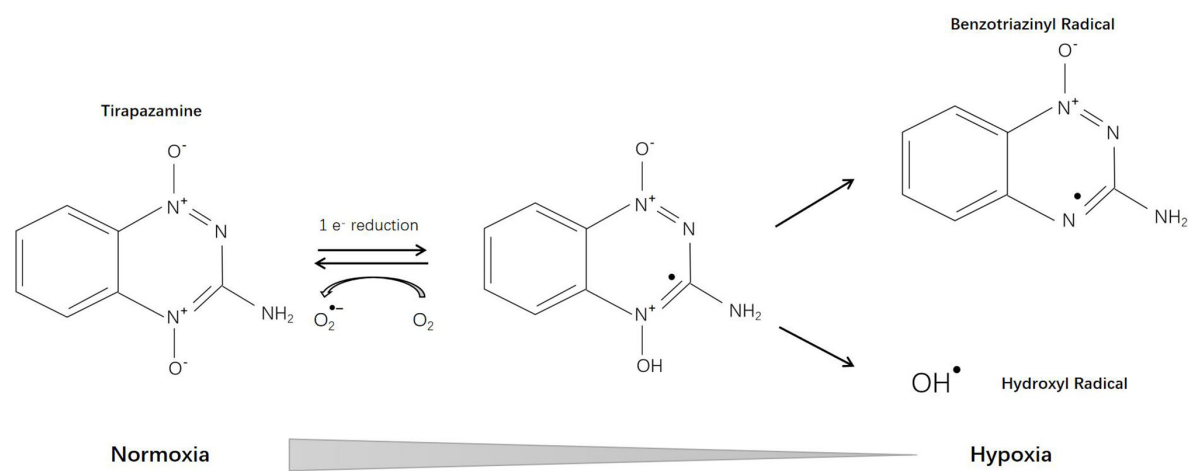

FIGURE 2 | Reductive reaction of tirapazamine.

antineoplastic effects while sparing normal tissues (12, 32-38). As flavone acetic acid (FAA) reduces the blood supply of tumors, tirapazamine in combination with FAA could significantly enhance the antineoplastic efficacy of both drugs (39). Many studies have investigated the synergistic effect of tirapazamine and chemotherapy (such as cyclophosphamide, cisplatin, paclitaxel, etc.) or radioimmunotherapy (40-45). Tirapazamine, together with hyperthermia, electric pulses, etc. also exhibited encouraging antineoplastic efficacy (46-49). However, studies conducted by Adam et al. $(50,51)$ demonstrated that tirapazamine plus cisplatin and/or irradiation significantly increased toxicity and mortality.

In clinical trials, the reported adverse events associated with tirapazamine included muscle cramping, ototoxicity, granulocytopenia, nausea and vomiting, etc. $(52,53)$. Most phase 1 and 2 clinical trials have shown encouraging antineoplastic efficacy and tolerable toxicity (54-60). However, others, as well as two phase 3 clinical studies showed little benefit or significant toxicity (61-65).

\section{AQ4N}

AQ4N [1,4-bis $\{[2-($ dimethylamino-N-oxide)ethyl $]$ amino $\}-5,8-$ dihydroxyanthracene-9,10-dione], an aliphatic $\mathrm{N}$-oxide, was first reported in 1993 (66). Its prodrug has no intrinsic DNA binding affinity and thus is non-toxic. Under hypoxic conditions, AQ4N can be activated into AQ4 (with an intermediate product AQ4M) through a two-electron reduction mediated by CYP, which is DNA-affinic and possesses 1000 -fold cytotoxic potency compared with its prodrug (Figure 3). During the subsequent decade, Patterson and his team deeply investigated the pharmacology of AQ4N. They demonstrated that AQ4N combined with radiotherapy or chemotherapy (cisplatin, cyclophosphamide, thiotepa, mitoxantrone) showed enhanced antineoplastic effects (67-70). In 2003, they proposed a genedirected enzyme prodrug therapy (GDEPT) strategy using CYPs in order to facilitate the bioreduction of AQ4N (71). Other researchers also investigated the activation of $A Q 4 N$ by different types of CYPs and nitric oxide synthase (NOS) (72-75).

Many researchers have confirmed that AQ4N exerts antitumor effects in preclinical models of pancreatic cancer (76), bladder cancer and lung cancer (77), prostate cancer (78), gliosarcoma (79), etc., in both single-agent and combined chemotherapy, and in radiotherapy. Gieling et al. (80) demonstrated that AQ4N was more effective toward metastases in a fibrosarcoma-bearing mouse model (subcutaneous KHT tumors). Trédan et al. compared the penetration capacity of AQ4N and mitoxantrone through multi-layer cell cultures and<smiles>CN(C)CCNc1ccc(NCCN(C)C)c2c1C(=O)c1c(O)ccc(O)c1C2=O</smiles>

Normoxia

Hypoxia

FIGURE 3 | Reductive reaction of AQ4N. 
tumor xenografts, and found that AQ4N could penetrate deeply into the hypoxic regions of the tumor and that combination therapy of AQ4N with mitoxantrone showed decreased tumor growth (81). There is also evidence showed that AQ4N had antiangiogenic effects $(82,83)$.

The first phase 1 study of AQ4N was reported in 2007, in which 22 esophageal carcinoma patients received an AQ4N infusion followed by fractionated radiotherapy (84). Three of 22 patients had $>50 \%$ reductions in tumor volume and 9 had stable disease without dose-limiting toxicity. Albertella et al. enrolled 32 patients with different malignancies in a phase 1 study, and demonstrated that AQ4N was activated selectively in hypoxic regions of tumors and that it can penetrate the bloodbrain barrier (85). No objective antitumor effect was observed in another phase 1 clinical study conducted by Papadopoulos et al. (86).

In recent years, a series of new therapeutic strategies have been under development, including combination therapy with AQ4N and photodynamic therapy (PDT), vascular-targeted photodynamic therapy (VTP) (87-92). Feng et al. (93) developed a treatment strategy that combined PDT with AQ4N. Using an AQ4N-64Cu-hCe6-liposome in vivo PET probe, they were able to monitor tumor hypoxia status after illumination with light-emitting diode light and demonstrated that utilization of PDT-induced hypoxia to trigger hypoxia-targeted therapy achieved significant antineoplastic effects. Zhang et al. (94) showed that AQ4N combined with starvation therapy (by using stealth liposomes to deliver glucose oxidase together with prodrugs) exhibited similar enhancement of antitumor effects. These methodologies provide new insights for future cancer diagnosis and therapy.

\section{PR-104}

PR-104 is a 3,5-dinitrobenzamide-2-mustard. The water-soluble phosphate PR-104 can transform to a more lipophilic prodrug PR-104A (3,5-dinitrobenzamide-2-nitrogen mustard) systemically, and then, under hypoxic conditions, it can be further activated by reduction to $\mathrm{PR}-104 \mathrm{H}$ (5-hydroxylamine) and PR-104M (5-amine), allowing it to act as a DNA interstrand cross-linking agent in hypoxic cells and exert cytotoxic effects (95) (Figure 4). The reduction reaction is catalyzed anaerobically mainly by NADPH-cytochrome P450 reductase (96). There are studies demonstrating that PR-104 may also be reduced by aldoketo reductase (AKR) 1C3 anaerobically, which might cause systemic toxicity $(97,98)$. The sensitivity of PR-104 depends on the oxygenation status, reductase activity, and DNA repair ability (99). Two studies have revealed the bystander effect of PR-104 $(100,101)$.

In in vitro studies, the antitumor efficacy of PR-104 has been investigated in cervical squamous cell carcinoma ( $\mathrm{SiHa}$ cells), ovarian carcinoma (A2780 cells), non-small cell lung carcinoma (H1299 and A549 cells), colorectal carcinoma (RKO and HCT116 cells), hepatocellular carcinoma, etc., PR-104 as a single agent or in combination with radiotherapy or chemotherapy has shown different degrees of antineoplastic effects (95, 102-104).

In clinical trials, however, no or only partial responses were observed, but with obvious toxicities, mainly thrombocytopenia and neutropenia (105-108). However, PR-104 showed advantages in the treatment of leukemia. Evidence showed that in acute lymphoblastic leukemia, T-cell acute lymphoblastic leukemia, and acute myeloid leukemia, PR-104 decreased<smiles>COCCN(CCBr)c1c(C(=O)NCCOOC)cc([N+](=O)[O-])cc1[N+](=O)[O-]</smiles><smiles>CCCCOC(C)(C)C(C)(C)C</smiles><smiles>C1CCCCC1</smiles><smiles>COCCN(CCBr)c1c(C(=O)NCCO)cc(N)cc1[N+](=O)[O-]</smiles><smiles>[CH]</smiles>

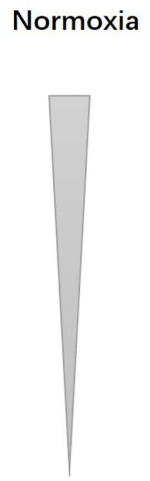

Hypoxia

FIGURE 4 | Reductive reaction of PR-104. 
tumor burden and prolonged survival in pre-clinical studies (109), and also was associated with disease response in a phase I/II clinical trial (110). The expression of AKR1C3 can be used as a biomarker to predict response to $\mathrm{PR}-104$ and patients screening (111).

\section{EO9 (APAZIQUONE)}

EO9 (Apaziquone) [3-hydroxy-5-aziridinyl-1-methyl-2(1Hindole-4,7-dione)prop-beta-en-alpha-ol], which is structurally related to mitomycin C, was first reported 1989 and has been deeply investigated since then. Pharmacological studies have shown that DT-diaphorase plays a vital role in the reduction of EO9 prodrug (112), implying that detection of DT-diaphorase activity might predict the sensitivity of certain tumors to EO9 (113-115) (Figure 5).

In vitro, EO9 was proved effective toward colon adenocarcinoma cells, melanoma cells, central nervous system tumors, renal cancer cells, oral squamous cell carcinoma, and lung cancer cells (including NSCLC and certain cell lines of small cell lung cancer). In vivo, gastric and colorectal adenocarcinoma, ovarian carcinoma, and breast carcinoma were sensitive while leukemia was found to be resistant to EO9 (116-118). Certain inducers such as 1,2-dithiole-3-thiones (D3T) could enhance DT-diaphorase activity, thereby increasing the sensitivity of EO9 $(119,120)$. However, some researchers pointed out that in vitro studies on DT-diaphorase activity are different from in vivo studies, and may result in different sensitivity measurements (121). Further pharmacological studies have shown that in the presence of oxygen, DT-diaphorase reduces EO9 through 2electron reduction, and the product is hydroquinone; while under hypoxic conditions, EO9 undergoes 1-electron reduction, and the product is semiquinone, which is more toxic than hydroquinone $(122,123)$. Therefore, EO9 may be more effective for hypoxic solid tumors $(124,125)$. Studies have also shown that the anti-tumor effect of EO9 is $\mathrm{pH}$-dependent, and may exert a tumor suppressor effect in tumor areas with low $\mathrm{pH}$ (pH5.5-7.0) (126).

For clinical trials, nephrotoxicity and proteinuria were observed in both phase 1 and phase 2 clinical studies, but only partial response or stable disease was achieved (127-131). The reason for these unsatisfactory results may be attributed to the instability of both semiquinone and hydroquinone, with a short half-life and poor permeability, which will be quickly removed in vivo (131-134). However, this special pharmacokinetic profile is ideal for local treatment $(135,136)$. Intravesical instillation of EO9 was well tolerated and effective for superficial bladder cancer, manifested by a higher complete remission rate and a lower recurrence rate (137-139). A recent study pointed out that EO9 may be inactivated by hematuria, which suggests that the timing of medication should be selected with this in mind in the design of future phase 3 clinical trials (140).

\section{TH-302 (EVOFOSFAMIDE)}

TH-302 (Evofosfamide), a second-generation HAP, consists of a 2-nitroimidazole moiety linked to bromo-iso-phosphoramide mustard (Br-IPM). Br-IPM is a DNA cross-linking agent. Under hypoxic conditions through a 2-nitroimidazole reduction reaction, TH-302 prodrug releases Br-IPM and perform cytotoxic effect (141) (Figure 6). Cytochrome P450 oxidoreductase (POR) also plays an important role in the reduction reaction and is the main determinant of cell sensitivity to TH-302 (142). Thus, the efficacy of TH-302 is highly dependent on the tumor type (143).

Many researchers have reported the antitumor efficacy of TH-302 as a single agent in malignancies including multiple myeloma, osteosarcoma, chondrosarcoma, neuroblastoma, rhabdomyosarcoma, breast cancer, non-small cell lung cancer, head and neck tumors, acute myeloid leukemia, etc. (144-152). The effect of TH-302 on spherical cells was significantly enhanced (153) and its activity was related to tumor hypoxic fractions (154), indicating that TH-302 had high hypoxic selectivity. The reported antineoplastic mechanisms include DNA fragmentation, cell cycle arrest, down-regulation of hypoxia-inducible factor- $1 \alpha$ expression, etc.

In addition to monotherapy, $\mathrm{TH}-302$ also showed synergistic effects with many traditional chemotherapy drugs, including doxorubicin, topotecan, paclitaxel, cisplatin, docetaxel, pemetrexed, irinotecan, gemcitabine, and temozolomide (155-157). TH-302 was able to inhibit the reoxygenation and

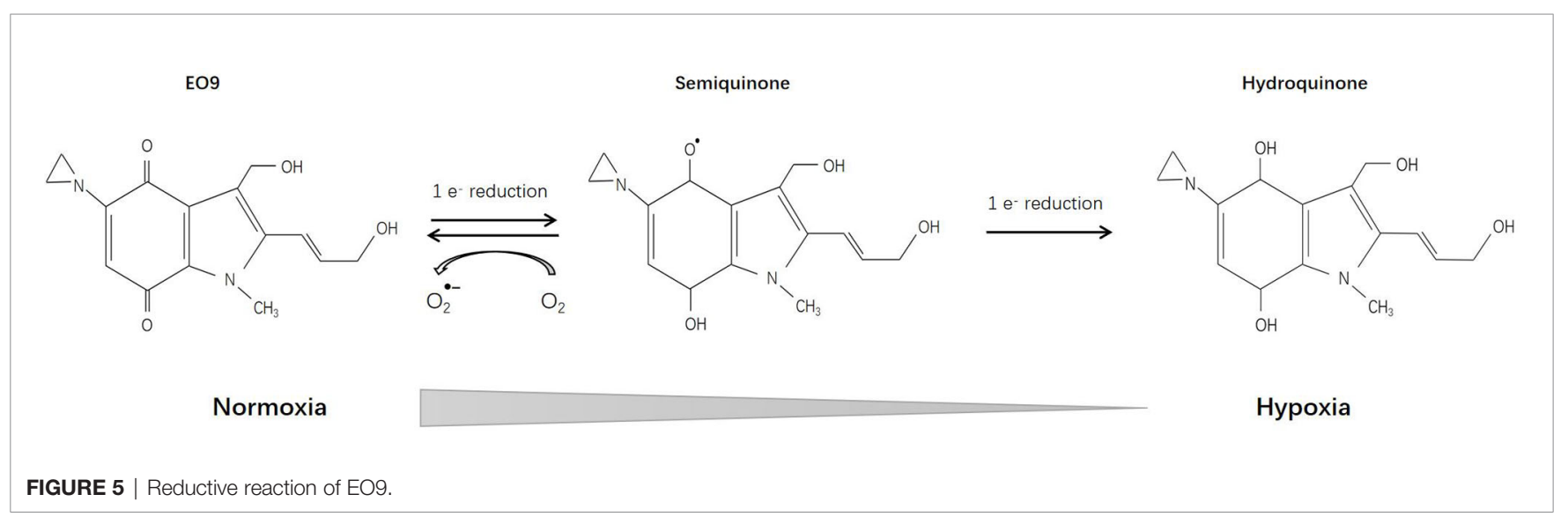




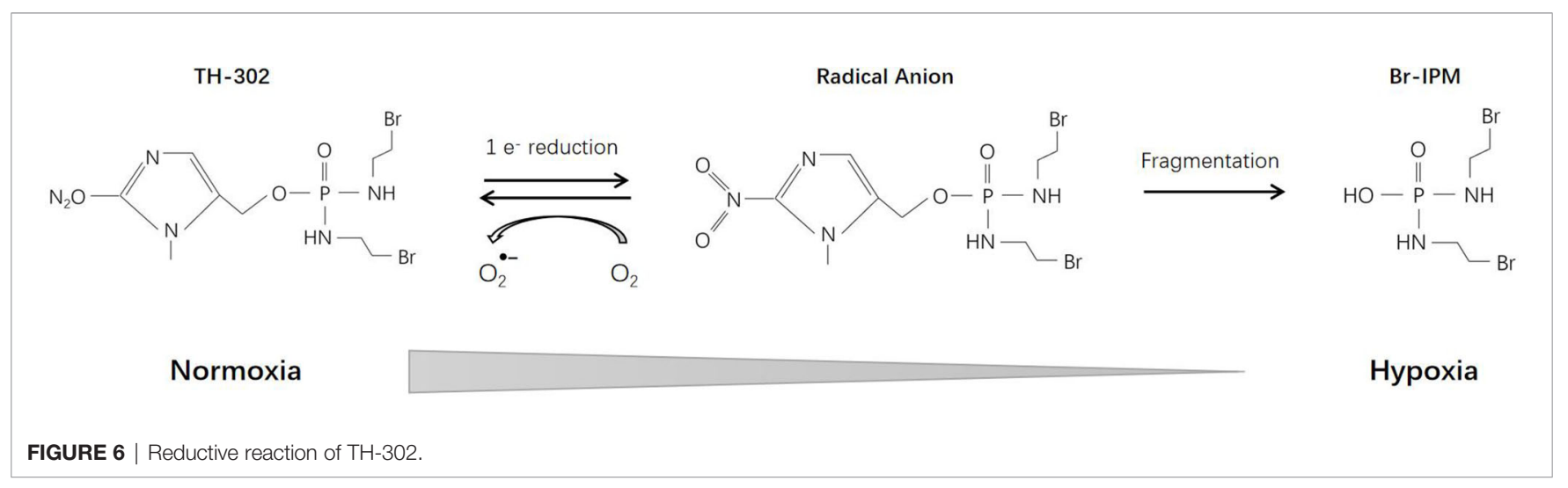

proliferation of hypoxic tumor cells that survived chemotherapy (158). Studies also revealed that the application of hypoxia inducers, such as Chk1 inhibitor, mTOR inhibitor, hydralazine, and pyruvate, enhanced the efficacy of TH-302 (159-161). TH-302 also has a radiosensitization effect. It exerts a synergistic effect when combined with radiotherapy (162-164). TH-302 has been shown to be beneficial in combination with conventional transarterial chemoembolization (cTACE) (165); anti-angiogenic therapy, such as VEGF-A inhibitor, sunitinib, and pazopanib (166-168); molecular targeted therapy, such as sorafenib and erlotinib (169, 170); and immunotherapy, such as CTLA-4 and PD-1 blockade $(171,172)$, where it also exerted a significant tumor inhibition effect. Recent evidence suggests that TH-302 can not only kill hypoxic pancreatic cancer cells, but also has the ability to improve the oxygenation status of residual tumor cells, so it may be useful to enhance the effect of radiotherapy and chemotherapy (173).

Since 2007, TH-302 has been in clinical trials. The main toxicities reported were skin and/or mucosal toxicity, thrombocytopenia, neutropenia, and myelosuppression (174-177). Several phase 1/2 clinical trials have reported encouraging results. For several types of tumors, including soft tissue sarcoma, pancreatic cancer, glioblastoma, and papillomavirus-negative head and neck squamous cell carcinoma, etc, TH-302 alone or in combination with other therapies showed varying degrees of antineoplastic activity $(171,175-178)$. It showed limited efficacy in the treatment of leukemia and failed in two phase 3 clinical trials (179-181). Researchers analyzed the possible reasons, including the lack of patient screening based on tumor hypoxia status $(182,183)$, antagonism between drugs (184), and drug formulation changes (185). Further research is still in progress.

\section{SN30000}

SN30000 [3-(3-Morpholinopropyl)-7,8-dihydro-6H-indeno[5,6e] $[1,2,4]$ triazine 1,4 -dioxide], previously known as CEN-209, is a second-generation benzotriazine- $\mathrm{N}$-oxide hypoxia-activated prodrug and a modified analogue of tirapazamine (Figure 7). Currently, it is still in the stage of preclinical research. Several studies have confirmed that SN30000 possesses similar pharmacological mechanisms (186) to tirapamine, but is superior in terms of antineoplastic effects and hypoxia selectivity (187).

Mao et al. (188) proved that, compared with monolayer tumor cells, SN30000 has higher activity on tumor spheroids, and when combined with radiation, it can cause significant tumor spheroid growth delay. Moreover, when used together with or before gemcitabine, SN30000 can effectively inhibit the proliferation of reoxygenated tumor cells (189). EF5 binding may be a promising biomarker for hypoxia stratification and SN30000 treatment response assessment $(190,191)$.
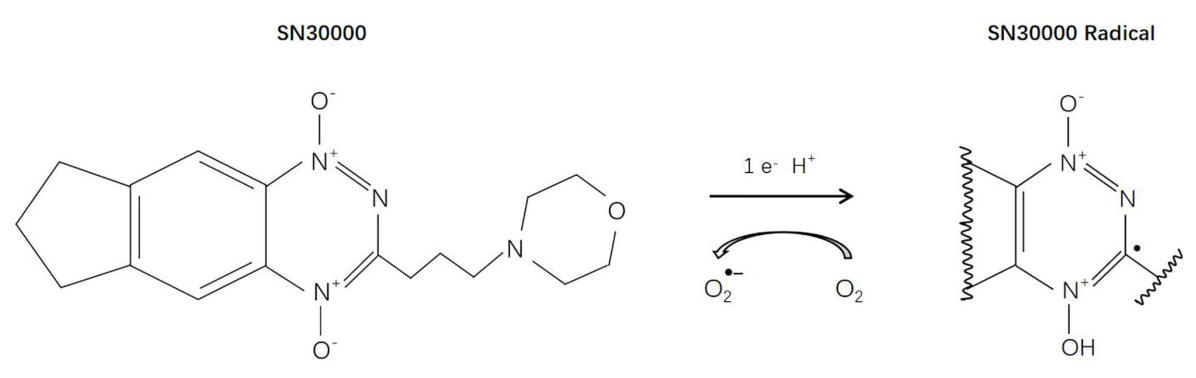

Normoxia

Hypoxia

FIGURE 7 | Reductive reaction of SN30000. 
TABLE 1 | Summary points.

\section{Summary points}

Current Research Status:

-At present, the research of HAPS is mostly limited to the curative effect of macroscopic solid tumors. However, the results are not satisfactory.

-Evidence showed that hypoxic tumor cells could only survive for 2-3 days in vivo, suggesting that in vivo hypoxic cells are destined to enter necrosis in vivo and that hypoxia-targeting therapy of macroscopic tumors should be revisited. Suggestions For Future Investigations:

- Our experimental evidence showed that micro-metastases $(<1 \mathrm{~mm}$ in diameter) and tumor cells in ascites and pleural effusion were severely hypoxic and in low proliferation state.

- They were insensitivity to traditional radiotherapy and chemotherapy.

-Micro-metastases (<1 mm in diameter) and tumor cells in ascites and pleural effusion are more suitable therapeutic targets for HAPs.

\section{CONCLUSIONS AND SUGGESTIONS FOR FUTURE INVESTIGATIONS}

Since the 1980s, HAPs have been developed and validated step by step, from preclinical to clinical. Despite their antineoplastic effects, their drawbacks and limitations have also been revealed by many studies. Here, we summarize the past experience and the latest research progress, and propose the following directions for future research (Table 1):

First, screening methods need to be developed based on tumor hypoxia to select the best candidates for this type of therapy. A growing number of studies have shown that PET/CT imaging can be an effective method to monitor HAPs uptake and therapeutic response $(148,190,192)$. Second, biomarkers to predict drug sensitivity are needed. Since HAP is a bioreductive drug, it requires specific enzymes to complete the reduction reaction. Therefore, the detection of specific enzymes can play a role in predicting drug sensitivity $(112,142)$. In addition, experiments conducted by our group and others showed that hypoxic tumor cells could only survive for 2-3 days in vivo $(193,194)$, suggesting that in vivo hypoxic cells are destined to enter necrosis in vivo and that hypoxia-targeting therapy of macroscopic tumors should be revisited.

\section{REFERENCES}

1. Evans SM, Koch CJ. Prognostic Significance of Tumor Oxygenation in Humans. Cancer Lett (2003) 195(1):1-16. doi: 10.1016/s0304-3835(03)00012-0

2. Challapalli A, Carroll L, Aboagye EO. Molecular Mechanisms of Hypoxia in Cancer. Clin Transl Imaging (2017) 5(3):225-53. doi: 10.1007/s40336017-0231-1

3. Bristow RG, Hill RP. Hypoxia and Metabolism. Hypoxia, DNA Repair and Genetic Instability. Nat Rev Cancer (2008) 8(3):180-92. doi: 10.1038/nrc2344

4. Carmeliet P, Jain RK. Molecular Mechanisms and Clinical Applications of Angiogenesis. Nature (2011) 19473(7347):298-307. doi: 10.1038/nature10144

5. Lum JJ, Bui T, Gruber M, Gordan JD, DeBerardinis RJ, Covello KL, et al. The Transcription Factor HIF-1alpha Plays a Critical Role in the Growth FactorDependent Regulation of Both Aerobic and Anaerobic Glycolysis. Genes Dev (2007) 21(9):1037-49. doi: 10.1101/gad.1529107

6. Joseph JP, Harishankar MK, Pillai AA, Devi A. Hypoxia Induced EMT: A Review on the Mechanism of Tumor Progression and Metastasis in OSCC. Oral Oncol (2018) 80:23-32. doi: 10.1016/j.oraloncology.2018.03.004

7. Li XF, Carlin S, Urano M, Russell J, Ling CC, O’Donoghue JA. Visualization of Hypoxia in Microscopic Tumors by Immunofluorescent Microscopy. Cancer Res (2007) 67(16):7646-53. doi: 10.1158/0008-5472.CAN-06-4353
Hypoxia is not only a characteristic of macroscopic tumors. In 2007, Li et al. reported that peritoneal disseminated micrometastases $(<1 \mathrm{~mm}$ in diameter) were severely hypoxic and in low proliferation state $(7,8,195-197)$. This hypoxic state of early micrometastases likely confers insensitivity to traditional radiotherapy and chemotherapy, making them suitable therapeutic targets for HAPs. HAPs may have the potential to prevent them from developing into macroscopic tumors, thereby reducing the metastatic rate of tumors. Our group is working to further confirm the efficacy of HAPs on such tumors and its effect on early tumor metastasis.

\section{DATA AVAILABILITY STATEMENT}

The original contributions presented in the study are included in the article/supplementary files. Further inquiries can be directed to the corresponding author.

\section{AUTHOR CONTRIBUTIONS}

YL performed the literature search and wrote the manuscript. LZ performed the literature search and figure editing. X-FL contributed to write and revise the manuscript. All authors contributed to the article and approved the submitted version.

\section{ACKNOWLEDGMENTS}

The authors' research is supported in part by a grant from Shenzhen People's Hospital for "Climbing" Program (X-FL), and a Shenzhen Science and Technology Project grant (JCYJ20190806151003583) (X-FL). We thank Libby Cone, MD, MA, from Effective Medical English (www.effectivemedicalenglish.com/cone@effective medicalenglish) for editing a draft of this manuscript.

8. Li XF, O'Donoghue JA. Hypoxia in Microscopic Tumors. Cancer Lett (2008) 264(2):172-80. doi: 10.1016/j.canlet.2008.02.037

9. Horsman MR, Overgaard J. The Impact of Hypoxia and Its Modification of the Outcome of Radiotherapy. J Radiat Res (2016) 57(Suppl 1):i90-8. doi: $10.1093 /$ jrr/rrw007

10. Manoochehri Khoshinani H, Afshar S, Najafi R. Hypoxia: A Double-Edged Sword in Cancer Therapy. Cancer Invest (2016) 34(10):536-45. doi: 10.1080/ 07357907.2016.1245317

11. Kim JY, Lee JY. Targeting Tumor Adaption to Chronic Hypoxia: Implications for Drug Resistance, and How it Can be Overcome. Int $J$ Mol Sci (2017) 18(9):1854. doi: 10.3390/ijms18091854

12. Zeman EM, Brown JM, Lemmon MJ, Hirst VK, Lee WW. Sr-4233: A New Bioreductive Agent With High Selective Toxicity for Hypoxic Mammalian Cells. Int J Radiat Oncol Biol Phys (1986) 12(7):1239-42. doi: 10.1016/03603016(86)90267-1

13. Laderoute K, Wardman P, Rauth AM. Molecular Mechanisms for the HypoxiaDependent Activation of 3-Amino-1,2,4-Benzotriazine-1,4-Dioxide ( $\mathrm{Sr} 4233$ ). Biochem Pharmacol (1988) 37(8):1487-95. doi: 10.1016/0006-2952(88)90010-x

14. Saunders MP, Patterson AV, Chinje EC, Harris AL, Stratford IJ. NADPH: Cytochrome C (P450) Reductase Activates Tirapazamine (SR4233) to Restore Hypoxic and Oxic Cytotoxicity in an Aerobic Resistant Derivative 
of the A549 Lung Cancer Cell Line. Br J Cancer (2000) 82(3):651-6. doi: 10.1054/bjoc.1999.0977

15. Riley RJ, Workman P. Enzymology of the Reduction of the Potent Benzotriazine-di-N-oxide Hypoxic Cell Cytotoxin SR 4233 (WIN 59075) by NAD(P)H: (Quinone Acceptor) Oxidoreductase (EC 1.6.99.2) Purified From Walker 256 Rat Tumour Cells. Biochem Pharmacol (1992) 43(2):16774. doi: 10.1016/0006-2952(92)90274-m

16. Patterson AV, Robertson N, Houlbrook S, Stephens MA, Adams GE, Harris $\mathrm{AL}$, et al. The Role of DT-diaphorase in Determining the Sensitivity of Human Tumor Cells to Tirapazamine (Sr 4233). Int J Radiat Oncol Biol Phys (1994) 29(2):369-72. doi: 10.1016/0360-3016(94)90291-7

17. Elwell JH, Siim BG, Evans JW, Brown JM. Adaptation of Human Tumor Cells to Tirapazamine Under Aerobic Conditions: Implications of Increased Antioxidant Enzyme Activity to Mechanism of Aerobic Cytotoxicity. Biochem Pharmacol (1997) 54(2):249-57. doi: 10.1016/s0006-2952(97)00171-8

18. Wang J, Biedermann KA, Brown JM. Repair of DNA and Chromosome Breaks in Cells Exposed to SR 4233 Under Hypoxia or to Ionizing Radiation. Cancer Res (1992) 52(16):4473-7. doi: 10.1002/1097-0142(19920815) 70:4<903::AID-CNCR2820700432>3.0.CO;2

19. Kotandeniya D, Ganley B, Gates KS. Oxidative DNA Base Damage by the Antitumor Agent 3-amino-1,2,4-benzotriazine 1,4-Dioxide (Tirapazamine). Bioorg Med Chem Lett (2002) 12(17):2325-9. doi: 10.1016/s0960-894x(02) 00468-7

20. Birincioglu M, Jaruga P, Chowdhury G, Rodriguez H, Dizdaroglu M, Gates KS. Dna Base Damage by the Antitumor Agent 3-amino-1,2,4-benzotriazine 1,4-Dioxide (Tirapazamine). J Am Chem Soc (2003) 125(38):11607-15. doi: 10.1021/ja0352146

21. Evans JW, Yudoh K, Delahoussaye YM, Brown JM. Tirapazamine Is Metabolized to Its DNA-Damaging Radical by Intranuclear Enzymes. Cancer Res (1998) 58(10):2098-101.

22. Aboagye EO, Dillehay LE, Bhujwalla ZM, Lee DJ. Hypoxic Cell Cytotoxin Tirapazamine Induces Acute Changes in Tumor Energy Metabolism and Ph: A 31p Magnetic Resonance Spectroscopy Study. Radiat Oncol Investig (1998) 6 (6):249-54. doi: 10.1002/(SICI)1520-6823(1998)6:6<249::AID-ROI1>3.0.CO;2-C

23. Skarsgard LD, Vinczan A, Skwarchuk MW, Chaplin DJ. The Effect of Low $\mathrm{Ph}$ and Hypoxia on the Cytotoxic Effects of SR4233 and Mitomycin C In Vitro. Int J Radiat Oncol Biol Phys (1994) 29(2):363-7. doi: 10.1016/03603016(94)90290-9

24. Koch CJ. Unusual Oxygen Concentration Dependence of Toxicity of SR4233, a Hypoxic Cell Toxin. Cancer Res (1993) 53(17):3992-7. doi: 10.1007/ BF01518522

25. Durand RE, Olive PL. Physiologic and Cytotoxic Effects of Tirapazamine in Tumor-Bearing Mice. Radiat Oncol Investig (1997) 5(5):213-9. doi: 10.1002/ (SICI) 1520-6823(1997)5:5<213::AID-ROI1>3.0.CO;2-0

26. Lin PS, Ho KC, Yang SJ. Tirapazamine (SR 4233) Interrupts Cell Cycle Progression and Induces Apoptosis. Cancer Lett (1996) 105(2):249-55. doi: 10.1016/0304-3835(96)04292-9

27. Hanauske AR, Ross M, Degen D, Hilsenbeck SG, Von Hoff DD. In Vitro Activity of the Benzotriazine Dioxide SR 4233 Against Human Tumour Colony-Forming Units. Eur J Cancer (1993) 29A(3):423-5. doi: 10.1016/ 0959-8049(93)90400-a

28. Hong B, Lui VW, Hui EP, Ng MH, Cheng SH, Sung FL, et al. HypoxiaTargeting by Tirapazamine (Tpz) Induces Preferential Growth Inhibition of Nasopharyngeal Carcinoma Cells With Chk1/2 Activation. Invest New Drugs (2011) 29(3):401-10. doi: 10.1007/s10637-009-9356-Z

29. Govaert KM, Nijkamp MW, Emmink BL, Steller EJ, Minchinton AI, Kranenburg O, et al. Effects of Tirapazamine on Experimental Colorectal Liver Metastases After Radiofrequency Ablation. Br J Surg (2012) 99(4):56775. doi: $10.1002 / b j s .8668$

30. Brown JM. Exploiting Tumour Hypoxia and Overcoming Mutant P53 With Tirapazamine. Br J Cancer (1998) 77(Suppl 4):12-4. doi: 10.1038/bjc.1998.430

31. Yang B, Reynolds CP. Tirapazamine Cytotoxicity for Neuroblastoma is $\mathrm{p} 53$ Dependent. Clin Cancer Res (2005) 11(7):2774-80. doi: 10.1158/10780432.CCR-04-2382

32. Brown JM, Lemmon MJ. Potentiation by the Hypoxic Cytotoxin SR 4233 of Cell Killing Produced by Fractionated Irradiation of Mouse Tumors. Cancer Res (1990) 50(24):7745-9. doi: 10.1002/1097-0142(19901215)66:12<2673:: AID-CNCR2820661235>3.0.CO
33. Minchinton AI, Brown JM. Enhancement of the Cytotoxicity of SR 4233 to Normal and Malignant Tissues by Hypoxic Breathing. Br J Cancer (1992) 66 (6):1053-8. doi: 10.1038/bjc.1992.409

34. el-Said A, Menke D, Dorie MJ, Brown JM. Comparison of the Effectiveness of Tirapazamine and Carbogen With Nicotinamide in Enhancing the Response of a Human Tumor Xenograft to Fractionated Irradiation. Radiat Oncol Investig (1999) 7(3):163-9. doi: 10.1002/(SICI)1520-6823 (1999)7:3<163::AID-ROI5>3.0.CO;2-M

35. Shibata T, Shibamoto Y, Sasai K, Oya N, Murata R, Takagi T, et al. Comparison of In Vivo Efficacy of Hypoxic Cytotoxin Tirapazamine and Hypoxic Cell Radiosensitizer Ku-2285 in Combination With Single and Fractionated Irradiation. Jpn J Cancer Res (1996) 87(1):98-104. doi: 10.1111/ j.1349-7006.1996.tb00206.x

36. Friery OP, Hejmadi MV, McKeown SR. Dna Damage Induced in T50/80 Tumour Cells Following Exposure to the Bioreductive Drug Tirapazamine in Combination With a Single Dose of Radiation (12gy). Biochem Soc Trans (1997) 25(1):135S. doi: 10.1042/bst025135s

37. Zhang M, Stevens G. Effect of Radiation and Tirapazamine (Sr-4233) on Three Melanoma Cell Lines. Melanoma Res (1998) 8(6):510-5. doi: 10.1097/ 00008390-199812000-00006

38. Masunaga SI, Tano K, Sanada Y, Sakurai Y, Tanaka H, Suzuki M, et al. Effect of Tirapazamine, Metformin or Mild Hyperthermia on Recovery From Radiation-Induced Damage in Pimonidazole-Unlabeled Quiescent Tumor Cells. World J Oncol (2017) 8(5):137-46. doi: 10.14740/wjon1058w

39. Cliffe S, Taylor ML, Rutland M, Baguley BC, Hill RP, Wilson WR. Combining Bioreductive Drugs (SR 4233 or SN 23862) With the Vasoactive Agents Flavone Acetic Acid or 5,6-Dimethylxanthenone Acetic Acid. Int J Radiat Oncol Biol Phys (1994) 29(2):373-7. doi: 10.1016/03603016(94)90292-5

40. Masunaga S, Ono K, Hori H, Shibata T, Suzuki M, Kinashi Y, et al. Effects of Bioreductive Agents, Tirapazamine and Mitomycin C, on Quiescent Cell Populations in Solid Tumors, Evaluated by Micronucleus Assay. Jpn J Cancer Res (1997) 88(9):907-14. doi: 10.1111/j.1349-7006.1997.tb00468.x

41. Weitman S, Mangold G, Marty J, Dexter D, Hilsenbeck S, Rake J, et al. Evidence of Enhanced In Vivo Activity Using Tirapazamine With Paclitaxel and Paraplatin Regimens Against the MV-522 Human Lung Cancer Xenograft. Cancer Chemother Pharmacol (1999) 43(5):402-8. doi: 10.1007/ s002800050914

42. Jounaidi Y, Waxman DJ. Combination of the Bioreductive Drug Tirapazamine With the Chemotherapeutic Prodrug Cyclophosphamide for P450/P450-Reductase-Based Cancer Gene Therapy. Cancer Res (2000) 60(14):3761-9. doi: 10.1016/S0165-4608(00)00214-4

43. Masunaga S, Ono K, Hori H, Suzuki M, Kinashi Y, Takagaki M, et al. Change in Oxygenation Status in Intratumour Total and Quiescent Cells Following Gamma-Ray Irradiation, Tirapazamine Administration, Cisplatin Injection and Bleomycin Treatment. Br J Radiol (2000) 73(873):978-86. doi: 10.1259/ bjr.73.873.11064652

44. Doloff JC, Khan N, Ma J, Demidenko E, Swartz HM, Jounaidi Y. Increased Tumor Oxygenation and Drug Uptake During Anti-Angiogenic Weekly Low Dose Cyclophosphamide Enhances the Anti-Tumor Effect of Weekly Tirapazamine. Curr Cancer Drug Targets (2009) 9(6):777-88. doi: 10.2174/ 156800909789271503

45. Wilder RB, Langmuir VK, Mendonca HL, Goris ML, Knox SJ. Local Hyperthermia and SR 4233 Enhance the Antitumor Effects of Radioimmunotherapy in Nude Mice With Human Colonic Adenocarcinoma Xenografts. Cancer Res (1993) 53(13):3022-7. doi: 10.1007/BF01517047

46. Masunaga S, Nagasawa H, Uto Y, Hori H, Nagata K, Suzuki M, et al. The Usefulness of Mild Temperature Hyperthermia Combined With Continuous Tirapazamine Administration Under Reduced Dose-Rate Irradiation With Gamma-Rays. Int J Hyperthermia (2007) 23(1):29-35. doi: 10.1080/ 02656730601135366

47. Masunaga S, Liu Y, Sakurai Y, Tanaka H, Suzuki M, Kondo N, et al. Usefulness of Combined Treatment With Continuous Administration of Tirapazamine and Mild Temperature Hyperthermia in $\gamma$-Ray Irradiation in Terms of Local Tumour Response and Lung Metastatic Potential. Int J Hyperthermia (2012) 28(7):636-44. doi: 10.3109/02656736.2012.714517

48. Broekgaarden M, Weijer R, van Wijk AC, Cox RC, Egmond MR, Hoebe R, et al. Photodynamic Therapy With Liposomal Zinc Phthalocyanine and 
Tirapazamine Increases Tumor Cell Death Via DNA Damage. J BioMed Nanotechnol (2017) 13(2):204-20. doi: 10.1166/jbn.2017.2327

49. Lin WH, Yeh SH, Yeh KH, Chen KW, Cheng YW, Su TH, et al. HypoxiaActivated Cytotoxic Agent Tirapazamine Enhances Hepatic Artery LigationInduced Killing of Liver Tumor in HBx Transgenic Mice. Proc Natl Acad Sci USA (2016) 113(42):11937-42. doi: 10.1073/pnas.1613466113

50. Adam M, Ottenjann S, Künzel G, Busch R, Erhardt W, Nieder C, et al. Evaluation of the Toxicity of Tirapazamine Plus Cisplatin in a Mouse Tumor Model. Strahlenther Onkol (2006) 182(4):231-9. doi: 10.1007/s00066-006-1506-Z

51. Adam M, Bayer C, Henke J, Grosu A, Molls M, Nieder C. Tirapazamine Plus Cisplatin and Irradiation in a Mouse Model: Improved Tumor Control at the Cost of Increased Toxicity. J Cancer Res Clin Oncol (2008) 134(2):137-46. doi: 10.1007/s00432-007-0260-7

52. Johnson CA, Kilpatrick D, von Roemeling R, Langer C, Graham MA, Greenslade D, et al. Phase I Trial of Tirapazamine in Combination With Cisplatin in a Single Dose Every 3 Weeks in Patients With Solid Tumors. J Clin Oncol (1997) 15(2):773-80. doi: 10.1200/JCO.1997.15.2.773

53. Hoff PM, Saad ED, Ravandi-Kashani F, Czerny E, Pazdur R. Phase I Trial of I.V. Administered Tirapazamine Plus Cyclophosphamide. Anticancer Drugs (2001) 12(6):499-503. doi: 10.1097/00001813-200107000-00002

54. Lara PNJr, Frankel P, Mack PC, Gumerlock PH, Galvin I, Martel CL, et al. Tirapazamine Plus Carboplatin and Paclitaxel in Advanced Malignant Solid Tumors: A California Cancer Consortium Phase I and Molecular Correlative Study. Clin Cancer Res (2003) 9(12):4356-62. doi: 10.1093/carcin/bgg164

55. Aquino VM, Weitman SD, Winick NJ, Blaney S, Furman WL, Kepner JL, et al. Phase I Trial of Tirapazamine and Cyclophosphamide in Children With Refractory Solid Tumors: A Pediatric Oncology Group Study. J Clin Oncol (2004) 22(8):1413-9. doi: 10.1200/JCO.2004.07.111

56. Cohen EE, Rosine D, Haraf DJ, Loh E, Shen L, Lusinchi A, et al. Phase I Trial of Tirapazamine, Cisplatin, and Concurrent Accelerated Boost Reirradiation in Patients With Recurrent Head and Neck Cancer. Int J Radiat Oncol Biol Phys (2007) 67(3):678-84. doi: 10.1016/j.ijrobp.2006.09.056

57. Smith HO, Jiang CS, Weiss GR, Hallum AV 3rd, Liu PY, Robinson WR 3rd, et al. Tirapazamine Plus Cisplatin in Advanced or Recurrent Carcinoma of the Uterine Cervix: A Southwest Oncology Group Study. Int J Gynecol Cancer (2006) 16(1):298-305. doi: 10.1111/j.1525-1438.2006.00339.x

58. Reck M, von Pawel J, Nimmermann C, Groth G, Gatzemeier U. Phase II-trial of Tirapazamine in Combination With Cisplatin and Gemcitabine in Patients With Advanced Non-Small-Cell-Lung-Cancer (NSCLC). Pneumologie (2004) 58(12):845-9. doi: 10.1055/s-2004-830056

59. Covens A, Blessing J, Bender D, Mannel R, Morgan M. Gynecologic Oncology Group. A Phase II Evaluation of Tirapazamine Plus Cisplatin in the Treatment of Recurrent Platinum-Sensitive Ovarian or Primary Peritoneal Cancer: A Gynecologic Oncology Group Study. Gynecol Oncol (2006) 100(3):586-90. doi: 10.1016/j.ygyno.2005.09.032

60. Maluf FC, Leiser AL, Aghajanian C, Sabbatini P, Pezzulli S, Chi DS, et al. Phase II Study of Tirapazamine Plus Cisplatin in Patients With Advanced or Recurrent Cervical Cancer. Int J Gynecol Cancer (2006) 16(3):1165-71. doi: 10.1111/j.1525-1438.2006.00454.x

61. Ghatage P, Sabagh H. Is There a Role for Tirapazamine in the Treatment of Cervical Cancer? Expert Opin Drug Metab Toxicol (2012) 8(12):1589-97. doi: $10.1517 / 17425255.2012 .730518$

62. Rischin D, Narayan K, Oza AM, Mileshkin L, Bernshaw D, Choi J, et al. Phase 1 Study of Tirapazamine in Combination With Radiation and Weekly Cisplatin in Patients With Locally Advanced Cervical Cancer. Int J Gynecol Cancer (2010) 20(5):827-33. doi: 10.1111/IGC.0b013e3181dc827e

63. Le QT, Taira A, Budenz S, Jo Dorie M, Goffinet DR, Fee WE, et al. Mature Results From a Randomized Phase II Trial of Cisplatin Plus 5-Fluorouracil and Radiotherapy With or Without Tirapazamine in Patients With Resectable Stage IV Head and Neck Squamous Cell Carcinomas. Cancer (2006) 106(9):1940-9. doi: 10.1002/cncr.21785

64. Williamson SK, Crowley JJ, Lara PNJr, McCoy J, Lau DH, Tucker RW, et al. Phase III Trial of Paclitaxel Plus Carboplatin With or Without Tirapazamine in Advanced Non-Small-Cell Lung Cancer: Southwest Oncology Group Trial S0003. J Clin Oncol (2005) 23(36):9097-104. doi: 10.1200/ JCO.2005.01.3771

65. Rischin D, Peters LJ, O'Sullivan B, Giralt J, Fisher R, Yuen K, et al. Tirapazamine, Cisplatin, and Radiation Versus Cisplatin and Radiation for
Advanced Squamous Cell Carcinoma of the Head and Neck (Trog 02.02, Headstart): A Phase III Trial of the Trans-Tasman Radiation Oncology Group. J Clin Oncol (2010) 28(18):2989-95. doi: 10.1200/JCO.2009.27.4449

66. Patterson LH. Rationale for the Use of Aliphatic N-oxides of Cytotoxic Anthraquinones as Prodrug DNA Binding Agents: A New Class of Bioreductive Agent. Cancer Metastasis Rev (1993) 12(2):119-34. doi: 10.1007/ bf00689805

67. McKeown SR, Hejmadi MV, McIntyre IA, McAleer JJ, Patterson LH. AQ4N: An Alkylaminoanthraquinone N-Oxide Showing Bioreductive Potential and Positive Interaction With Radiation In Vivo. Br J Cancer (1995) 72(1):76-81. doi: 10.1038/bjc. 1995.280

68. Hejmadi MV, McKeown SR, Friery OP, McIntyre IA, Patterson LH, Hirst DG. DNA Damage Following Combination of Radiation With the Bioreductive Drug AQ4N: Possible Selective Toxicity to Oxic and Hypoxic Tumour Cells. Br J Cancer (1996) 73(4):499-505. doi: 10.1038/bjc.1996.87

69. Patterson LH, McKeown SR, Ruparelia K, Double JA, Bibby MC, Cole S, et al. Enhancement of Chemotherapy and Radiotherapy of Murine Tumours by AQ4N, a Bioreductively Activated Anti-Tumour Agent. Br J Cancer (2000) 82(12):1984-90. doi: 10.1054/bjoc.2000.1564

70. Gallagher R, Hughes CM, Murray MM, Friery OP, Patterson LH, Hirst DG, et al. The Chemopotentiation of Cisplatin by the Novel Bioreductive Drug AQ4N. Br J Cancer (2001) 85(4):625-9. doi: 10.1054/bjoc.2001.1975

71. McCarthy HO, Yakkundi A, McErlane V, Hughes CM, Keilty G, Murray M, et al. Bioreductive GDEPT Using Cytochrome P450 3A4 in Combination With AQ4N. Cancer Gene Ther (2003) 10(1):40-8. doi: 10.1038/ sj.cgt.7700522

72. Nishida CR, Lee M, de Montellano PR. Efficient Hypoxic Activation of the Anticancer Agent AQ4N by CYP2S1 and CYP2W1. Mol Pharmacol (2010) 78(3):497-502. doi: 10.1124/mol.110.065045

73. Xiao Y, Shinkyo R, Guengerich FP. Cytochrome P450 2S1 Is Reduced by NADPH-cytochrome P450 Reductase. Drug Metab Dispos (2011) 39(6):9446. doi: 10.1124/dmd.111.039321

74. Bebenek IG, Solaimani P, Bui P, Hankinson O. CYP2S1 Is Negatively Regulated by Corticosteroids in Human Cell Lines. Toxicol Lett (2012) 209(1):30-4. doi: 10.1016/j.toxlet.2011.11.020

75. Mehibel M, Singh S, Cowen RL, Williams KJ, Stratford IJ. Radiation Enhances the Therapeutic Effect of Banoxantrone in Hypoxic Tumour Cells With Elevated Levels of Nitric Oxide Synthase. Oncol Rep (2016) 35 (4):1925-32. doi: 10.3892/or.2016.4555

76. Lalani AS, Alters SE, Wong A, Albertella MR, Cleland JL, Henner WD. Selective Tumor Targeting by the Hypoxia-Activated Prodrug AQ4N Blocks Tumor Growth and Metastasis in Preclinical Models of Pancreatic Cancer. Clin Cancer Res (2007) 13(7):2216-25. doi: 10.1158/1078-0432.CCR-06-2427

77. Williams KJ, Albertella MR, Fitzpatrick B, Loadman PM, Shnyder SD, Chinje EC, et al. In Vivo Activation of the Hypoxia-Targeted Cytotoxin AQ4N in Human Tumor Xenografts. Mol Cancer Ther (2009) 8(12):326675. doi: 10.1158/1535-7163.MCT-09-0396

78. Ming L, Byrne NM, Camac SN, Mitchell CA, Ward C, Waugh DJ, et al. Androgen Deprivation Results in Time-Dependent Hypoxia in LNCaP Prostate Tumours: Informed Scheduling of the Bioreductive Drug AQ4N Improves Treatment Response. Int J Cancer (2013) 132(6):1323-32. doi: 10.1002/ijc.27796

79. Manley EJr, Waxman DJ. Impact of Tumor Blood Flow Modulation on Tumor Sensitivity to the Bioreductive Drug Banoxantrone. J Pharmacol Exp Ther (2013) 344(2):368-77. doi: 10.1124/jpet.112.200089

80. Gieling RG, Fitzmaurice RJ, Telfer BA, Babur M, Williams KJ. Dissemination Via the Lymphatic or Angiogenic Route Impacts the Pathology, Microenvironment and Hypoxia-Related Drug Response of Lung Metastases. Clin Exp Metastasis (2015) 32(6):567-77. doi: 10.1007/ s10585-015-9728-z

81. Trédan O, Garbens AB, Lalani AS, Tannock IF. The Hypoxia-Activated ProDrug AQ4N Penetrates Deeply in Tumor Tissues and Complements the Limited Distribution of Mitoxantrone. Cancer Res (2009) 69(3):940-7. doi: 10.1158/0008-5472.CAN-08-0676

82. Raghava S, Kompella UB. AQ4, an Antitumor Anthracenedione, Inhibits Endothelial Cell Proliferation and Vascular Endothelial Growth Factor Secretion: Implications for the Therapy of Ocular Neovascular Disorders. Eur J Pharmacol (2007) 568(1-3):68-74. doi: 10.1016/j.ejphar.2007.04.044 
83. O'Rourke M, Ward C, Worthington J, McKenna J, Valentine A, Robson T, et al. Evaluation of the Antiangiogenic Potential of AQ4N. Clin Cancer Res (2008) 14(5):1502-9. doi: 10.1158/1078-0432.CCR-07-1262

84. Steward WP, Middleton M, Benghiat A, Loadman PM, Hayward C, Waller $\mathrm{S}$, et al. The Use of Pharmacokinetic and Pharmacodynamic End Points to Determine the Dose of AQ4N, a Novel Hypoxic Cell Cytotoxin, Given With Fractionated Radiotherapy in a Phase I Study. Ann Oncol (2007) 18(6):1098103. doi: 10.1093/annonc/mdm 120

85. Albertella MR, Loadman PM, Jones PH, Phillips RM, Rampling R, Burnet N, et al. Hypoxia-Selective Targeting by the Bioreductive Prodrug AQ4N in Patients With Solid Tumors: Results of a Phase I Study. Clin Cancer Res (2008) 14(4):1096-104. doi: 10.1158/1078-0432.CCR-07-4020

86. Papadopoulos KP, Goel S, Beeram M, Wong A, Desai K, Haigentz M, et al. A Phase 1 Open-Label, Accelerated Dose-Escalation Study of the HypoxiaActivated Prodrug AQ4N in Patients With Advanced Malignancies. Clin Cancer Res (2008) 14(21):7110-5. doi: 10.1158/1078-0432.CCR-08-0483

87. Shen S, Wu Y, Li K, Wang Y, Wu J, Zeng Y, et al. Versatile Hyaluronic Acid Modified AQ4N-Cu(II)-gossypol Infinite Coordination Polymer Nanoparticles: Multiple Tumor Targeting, Highly Efficient Synergistic Chemotherapy, and Real-Time Self-Monitoring. Biomaterials (2018) 154:197-212. doi: 10.1016/j.biomaterials.2017.11.001

88. Zhang D, Wu M, Cai Z, Liao N, Ke K, Liu H, et al. Chemotherapeutic Drug Based Metal-Organic Particles for Microvesicle-Mediated Deep Penetration and Programmable Ph/NIR/Hypoxia Activated Cancer Photochemotherapy. Adv Sci (Weinh) (2018) 5(2):1700648. doi: 10.1002/advs.201700648

89. Luan X, Guan YY, Liu HJ, Lu Q, Zhao M, Sun D, et al. A Tumor VascularTargeted Interlocking Trimodal Nanosystem That Induces and Exploits Hypoxia. Adv Sci (Weinh) (2018) 5(8):1800034. doi: 10.1002/advs. 201800034

90. He Z, Dai Y, Li X, Guo D, Liu Y, Huang X, et al. Hybrid Nanomedicine Fabricated From Photosensitizer-Terminated Metal-Organic Framework Nanoparticles for Photodynamic Therapy and Hypoxia-Activated Cascade Chemotherapy. Small (2019) 15(4):e1804131. doi: 10.1002/smll.201804131

91. Li X, Zhao Y, Jiang W, Li S, Zhan M, Liu H, et al. Ultralong Circulating Choline Phosphate Liposomal Nanomedicines for Cascaded ChemoRadiotherapy. Biomater Sci (2019) 7(4):1335-44. doi: 10.1039/c9bm00051h

92. Ji Y, Lu F, Hu W, Zhao H, Tang Y, Li B, et al. Tandem Activated Photodynamic and Chemotherapy: Using $\mathrm{pH}$-Sensitive Nanosystems to Realize Different Tumour Distributions of Photosensitizer/Prodrug for Amplified Combination Therapy. Biomaterials (2019) 219:119393. doi: 10.1016/j.biomaterials.2019.119393

93. Feng L, Cheng L, Dong Z, Tao D, Barnhart TE, Cai W, et al. Theranostic Liposomes With Hypoxia-Activated Prodrug to Effectively Destruct Hypoxic Tumors Post-Photodynamic Therapy. ACS Nano (2017) 11 (1):927-37. doi: 10.1021/acsnano.6b07525

94. Zhang R, Feng L, Dong Z, Wang L, Liang C, Chen J, et al. Glucose \& Oxygen Exhausting Liposomes for Combined Cancer Starvation and HypoxiaActivated Therapy. Biomaterials (2018) 162:123-31. doi: 10.1016/ j.biomaterials.2018.02.004

95. Singleton RS, Guise CP, Ferry DM, Pullen SM, Dorie MJ, Brown JM, et al. DNA Cross-Links in Human Tumor Cells Exposed to the Prodrug PR-104A: Relationships to Hypoxia, Bioreductive Metabolism, and Cytotoxicity. Cancer Res (2009) 69(9):3884-91. doi: 10.1158/0008-5472.CAN-08-4023

96. Guise CP, Wang AT, Theil A, Bridewell DJ, Wilson WR, Patterson AV. Identification of Human Reductases That Activate the Dinitrobenzamide Mustard Prodrug PR-104A: A Role for NADPH:cytochrome P450 Oxidoreductase Under Hypoxia. Biochem Pharmacol (2007) 74(6):810-20. doi: 10.1016/j.bcp.2007.06.014

97. Guise CP, Abbattista MR, Singleton RS, Holford SD, Connolly J, Dachs GU, et al. The Bioreductive Prodrug PR-104A Is Activated Under Aerobic Conditions by Human Aldo-Keto Reductase 1C3. Cancer Res (2010) 70 (4):1573-84. doi: 10.1158/0008-5472.CAN-09-3237

98. Gu Y, Guise CP, Patel K, Abbattista MR, Li J, Sun X, et al. Reductive Metabolism of the Dinitrobenzamide Mustard Anticancer Prodrug PR-104 in Mice. Cancer Chemother Pharmacol (2011) 67(3):543-55. doi: 10.1007/ s00280-010-1354-5

99. Gu Y, Patterson AV, Atwell GJ, Chernikova SB, Brown JM, Thompson LH, et al. Roles of DNA Repair and Reductase Activity in the Cytotoxicity of the
Hypoxia-Activated Dinitrobenzamide Mustard PR-104A. Mol Cancer Ther (2009) 8(6):1714-23. doi: 10.1158/1535-7163.MCT-08-1209

100. Hicks KO, Myint H, Patterson AV, Pruijn FB, Siim BG, Patel K, et al. Oxygen Dependence and Extravascular Transport of Hypoxia-Activated Prodrugs: Comparison of the Dinitrobenzamide Mustard PR-104A and Tirapazamine. Int J Radiat Oncol Biol Phys (2007) 69(2):560-71. doi: 10.1016/j.ijrobp.2007.05.049

101. Foehrenbacher A, Patel K, Abbattista MR, Guise CP, Secomb TW, Wilson WR, et al. The Role of Bystander Effects in the Antitumor Activity of the Hypoxia-Activated Prodrug Pr-104. Front Oncol (2013) 3:263. doi: 10.3389/ fonc. 2013.00263

102. Cairns RA, Bennewith KL, Graves EE, Giaccia AJ, Chang DT, Denko NC. Pharmacologically Increased Tumor Hypoxia Can be Measured by $18 \mathrm{~F}$ Fluoroazomycin Arabinoside Positron Emission Tomography and Enhances Tumor Response to Hypoxic Cytotoxin PR-104. Clin Cancer Res (2009) 15 (23):7170-4. doi: 10.1158/1078-0432.CCR-09-1676

103. Graves EE, Vilalta M, Cecic IK, Erler JT, Tran PT, Felsher D, et al. Hypoxia in Models of Lung Cancer: Implications for Targeted Therapeutics. Clin Cancer Res (2010) 16(19):4843-52. doi: 10.1158/1078-0432.CCR-10-1206

104. Abbattista MR, Jamieson SM, Gu Y, Nickel JE, Pullen SM, Patterson AV, et al. Pre-Clinical Activity of PR-104 as Monotherapy and in Combination With Sorafenib in Hepatocellular Carcinoma. Cancer Biol Ther (2015) 16 (4):610-22. doi: 10.1080/15384047.2015.1017171

105. Jameson MB, Rischin D, Pegram M, Gutheil J, Patterson AV, Denny WA, et al. A Phase I Trial of PR-104, a Nitrogen Mustard Prodrug Activated by Both Hypoxia and Aldo-Keto Reductase 1C3, in Patients With Solid Tumors. Cancer Chemother Pharmacol (2010) 65(4):791-801. doi: 10.1007/s00280009-1188-1

106. McKeage MJ, Gu Y, Wilson WR, Hill A, Amies K, Melink TJ, et al. A Phase I Trial of PR-104, a Pre-Prodrug of the Bioreductive Prodrug PR-104A, Given Weekly to Solid Tumour Patients. BMC Cancer (2011) 11:432. doi: 10.1186/ 1471-2407-11-432

107. McKeage MJ, Jameson MB, Ramanathan RK, Rajendran J, Gu Y, Wilson WR, et al. Pr-104 a Bioreductive Pre-Prodrug Combined With Gemcitabine or Docetaxel in a Phase Ib Study of Patients With Advanced Solid Tumours. BMC Cancer (2012) 12:496. doi: 10.1186/1471-2407-12-496

108. Abou-Alfa GK, Chan SL, Lin CC, Chiorean EG, Holcombe RF, Mulcahy MF, et al. Pr-104 Plus Sorafenib in Patients With Advanced Hepatocellular Carcinoma. Cancer Chemother Pharmacol (2011) 68(2):539-45. doi: 10.1007/s00280-011-1671-3

109. Benito J, Shi Y, Szymanska B, Carol H, Boehm I, Lu H, et al. Pronounced Hypoxia in Models of Murine and Human Leukemia: High Efficacy of Hypoxia-Activated Prodrug PR-104. PLoS One (2011) 6(8):e23108. doi: 10.1371/journal.pone.0023108

110. Konopleva M, Thall PF, Yi CA, Borthakur G, Coveler A, Bueso-Ramos C, et al. Phase I/II Study of the Hypoxia-Activated Prodrug PR104 in Refractory/Relapsed Acute Myeloid Leukemia and Acute Lymphoblastic Leukemia. Haematologica (2015) 100(7):927-34. doi: 10.3324/ haematol.2014.118455

111. Moradi Manesh D, El-Hoss J, Evans K, Richmond J, Toscan CE, Bracken LS, et al. AKR1C3 Is a Biomarker of Sensitivity to PR-104 in Preclinical Models of T-Cell Acute Lymphoblastic Leukemia. Blood (2015) 126(10):1193-202. doi: 10.1182/blood-2014-12-618900

112. Walton MI, Sugget N, Workman P. The Role of Human and Rodent DTDiaphorase in the Reductive Metabolism of Hypoxic Cell Cytotoxins. Int J Radiat Oncol Biol Phys (1992) 22(4):643-7. doi: 10.1016/0360-3016(92) 90495-4

113. Smitskamp-Wilms E, Giaccone G, Pinedo HM, van der Laan BF, Peters GJ. DT-Diaphorase Activity in Normal and Neoplastic Human Tissues; an Indicator for Sensitivity to Bioreductive Agents? Br J Cancer (1995) 72 (4):917-21. doi: 10.1038/bjc.1995.433

114. Fitzsimmons SA, Workman P, Grever M, Paull K, Camalier R, Lewis AD. Reductase Enzyme Expression Across the National Cancer Institute Tumor Cell Line Panel: Correlation With Sensitivity to Mitomycin C and EO9. J Natl Cancer Inst (1996) 88(5):259-69. doi: 10.1093/jnci/88.5.259

115. Smitskamp-Wilms E, Peters GJ, Pinedo HM, van Ark-Otte J, Giaccone G. Chemosensitivity to the Indoloquinone EO9 Is Correlated With DTdiaphorase Activity and Its Gene Expression. Biochem Pharmacol (1994) 47(8):1325-32. doi: 10.1016/0006-2952(94)90330-1 
116. Hendriks HR, Pizao PE, Berger DP, Kooistra KL, Bibby MC, Boven E, et al. EO9: A Novel Bioreductive Alkylating Indoloquinone With Preferential Solid Tumour Activity and Lack of Bone Marrow Toxicity in Preclinical Models. Eur J Cancer (1993) 29A(6):897-906. doi: 10.1016/s0959-8049(05)80434-4

117. Roed H, Aabo K, Vindeløv L, Spang-Thomsen M, Christensen IB, Hansen HH. In Vitro and In Vivo Evaluation of the Indoloquinone EO-9 (NSC 382 459) Against Human Small Cell Carcinoma of the Lung. Eur J Cancer Clin Oncol (1989) 25(8):1197-201. doi: 10.1016/0277-5379(89)90415-x

118. Srivastava G, Somasundaram RT, Walfish PG, Ralhan R. Anticancer Activity of Apaziquone in Oral Cancer Cells and Xenograft Model: Implications for Oral Cancer Therapy. PLoS One (2015) 10(7):e0133735. doi: 10.1371/ journal.pone. 0133735

119. Begleiter A, Leith MK, Curphey TJ, Doherty GP. Induction of DTdiaphorase in Cancer Chemoprevention and Chemotherapy. Oncol Res (1997) 9(6-7):371-82. doi: 10.1016/0031-9422(91)83448-T

120. Doherty GP, Leith MK, Wang X, Curphey TJ, Begleiter A. Induction of DTdiaphorase by 1,2-dithiole-3-thiones in Human Tumour and Normal Cells and Effect on Anti-Tumour Activity of Bioreductive Agents. Br J Cancer (1998) 77(8):1241-52. doi: 10.1038/bjc.1998.209

121. Collard J, Matthew AM, Double JA, Bibby MC. EO9: Relationship Between DT-Diaphorase Levels and Response In Vitro and In Vivo. Br J Cancer (1995) 71(6):1199-203. doi: 10.1038/bjc.1995.233

122. Plumb JA, Workman P. Unusually Marked Hypoxic Sensitization to Indoloquinone EO9 and Mitomycin C in a Human Colon-Tumour Cell Line That Lacks DT-diaphorase Activity. Int J Cancer (1994) 56(1):134-9. doi: 10.1002/ijc.2910560124

123. Bailey SM, Wyatt MD, Friedlos F, Hartley JA, Knox RJ, Lewis AD, et al. Involvement of DT-diaphorase (Ec 1.6.99.2) in the DNA Cross-Linking and Sequence Selectivity of the Bioreductive Anti-Tumour Agent EO9. $\mathrm{Br} \mathrm{J}$ Cancer (1997) 76(12):1596-603. doi: 10.1038/bjc.1997.603

124. Bando T, Kasahara K, Shibata K, Numata Y, Heki U, Shirasaki H, et al. Cytotoxicity of a Novel Indoloquinone Eo9 in Hypoxic Non-Small-Cell Lung-Cancer Cell-Lines. Int J Oncol (1995) 7(4):789-93. doi: 10.3892/ ijo.7.4.789

125. Robertson N, Haigh A, Adams GE, Stratford IJ. Factors Affecting Sensitivity to EO9 in Rodent and Human Tumour Cells In Vitro: DT-diaphorase Activity and Hypoxia. Eur J Cancer (1994) 30A(7):1013-9. doi: 10.1016/ 0959-8049(94)90134-1

126. Phillips RM, Hulbert PB, Bibby MC, Sleigh NR, Double JA. In Vitro Activity of the Novel Indoloquinone EO-9 and the Influence of Ph on Cytotoxicity. $\mathrm{Br}$ J Cancer (1992) 65(3):359-64. doi: 10.1038/bjc.1992.73

127. McLeod HL, Graham MA, Aamdal S, Setanoians A, Groot Y, Lund B. Phase I Pharmacokinetics and Limited Sampling Strategies for the Bioreductive Alkylating Drug EO9. Eortc Early Clinical Trials Group. Eur J Cancer (1996) 32A(9):1518-22. doi: 10.1016/0959-8049(96)00120-7

128. Aamdal S, Lund B, Koier I, Houten M, Wanders J, Verweij J. Phase I Trial With Weekly EO9, a Novel Bioreductive Alkylating Indoloquinone, by the EORTC Early Clinical Study Group (Ecsg). Cancer Chemother Pharmacol (2000) 45:85-8. doi: 10.1007/PL00006748

129. Pavlidis N, Hanauske AR, Gamucci T, Smyth J, Lehnert M, te Velde A, et al. A Randomized Phase II Study With Two Schedules of the Novel Indoloquinone EO9 in Non-Small-Cell Lung Cancer: A Study of the EORTC Early Clinical Studies Group (Ecsg). Ann Oncol (1996) 7(5):52931. doi: 10.1093/oxfordjournals.annonc.a010645

130. Dirix LY, Tonnesen F, Cassidy J, Epelbaum R, ten Bokkel Huinink WW, Pavlidis N, et al. EO9 Phase II Study in Advanced Breast, Gastric, Pancreatic and Colorectal Carcinoma by the EORTC Early Clinical Studies Group. Eur J Cancer (1996) 32A(11):2019-22. doi: 10.1016/0959-8049(96)00226-2

131. Schellens JH, Dombernowsky P, Cassidy J, Epelbaum R, Dirix L, Cox EH, et al. Population Pharmacokinetics and Dynamics in Phase II Studies of the Novel Bioreductive Alkylating Cytotoxic Indoloquinone EO9. Anticancer Drugs (2001) 12(7):583-90. doi: 10.1097/00001813-200108000-00004

132. Butler J, Spanswick VJ, Cummings J. The Autoxidation of the Reduced Forms of EO9. Free Radic Res (1996) 25(2):141-8. doi: 10.3109/10715769609149919

133. Phillips RM, Hendriks HR, Peters GJ. Eortc-Pharmacology and Molecular Mechanism Group. EO9 (Apaziquone): From the Clinic to the Laboratory and Back Again. Br J Pharmacol (2013) 168(1):11-8. doi: 10.1111/j.14765381.2012.01996.x
134. Phillips RM, Hendriks HR, Sweeney JB, Reddy G, Peters GJ. Efficacy, Pharmacokinetic and Pharmacodynamic Evaluation of Apaziquone in the Treatment of Non-Muscle Invasive Bladder Cancer. Expert Opin Drug Metab Toxicol (2017) 13(7):783-91. doi: 10.1080/17425255.2017.1341490

135. Caramés Masana F, de Reijke TM. The Efficacy of Apaziquone in the Treatment of Bladder Cancer. Expert Opin Pharmacother (2017) 18 (16):1781-8. doi: 10.1080/14656566.2017.1392510

136. Puri R, Palit V, Loadman PM, Flannigan M, Shah T, Choudry GA, et al. Phase I/II Pilot Study of Intravesical Apaziquone (EO9) for Superficial Bladder Cancer. J Urol (2006) 176(4 Pt 1):1344-8. doi: 10.1016/j.juro.2006.06.047

137. Karsh L, Shore N, Saltzstein D, Bhat G, Reddy G, Allen LF, et al. Integrated Results of Two Multicenter, Randomised, Placebo Controlled, Double Blind, Phase 3 Trials (SPI-611/612) of Single Dose Intravesical Apaziquone Immediately Following Resection in Patients With Nonmuscle Invasive Bladder Cancer. J Urol (2016) 95(Supplement):e290. doi: 10.1016/ j.juro.2016.02.847

138. Witjes JA, Karsh L, Soloway M, Bhat G, Reddy G, Allen Y, et al. MP13-07 Improved Efficacy of Adjuvant, Single Dose Intravesical Apaziquone by Timing Post-Resection in Two Double Blind, Randomised, PlaceboControlled Phase 3 Studies in Non-Muscle Invasive Bladder Cancer. J Urol (2016) 195(Supplement):e136. doi: 10.1016/j.juro.2016.02.2488

139. Karsh L, Shore N, Soloway M, Bhat G, Reddy G, Leu SY, et al. Double-Blind, Randomized, Placebo-Controlled Studies Evaluating Apaziquone (E09, Qapzola $^{\mathrm{TM}}$ ) Intravesical Instillation Post Transurethral Resection of Bladder Tumors for the Treatment of Low-risk Non-Muscle Invasive Bladder Cancer. Bladder Cancer (2018) 4(3):293-301. doi: 10.3233/BLC180166

140. Phillips RM, Loadman PM, Reddy G. Inactivation of Apaziquone by Haematuria: Implications for the Design of Phase III Clinical Trials Against Non-Muscle Invasive Bladder Cancer. Cancer Chemother Pharmacol (2019) 83(6):1183-9. doi: 10.1007/s00280-019-03812-7

141. Duan JX, Jiao H, Kaizerman J, Stanton T, Evans JW, Lan L, et al. Potent and Highly Selective Hypoxia-Activated Achiral Phosphoramidate Mustards as Anticancer Drugs. J Med Chem (2008) 51(8):2412-20. doi: 10.1021/ jm701028q

142. Hunter FW, Young RJ, Shalev Z, Vellanki RN, Wang J, Gu Y, et al. Identification of P450 Oxidoreductase as a Major Determinant of Sensitivity to Hypoxia-Activated Prodrugs. Cancer Res (2015) 75 (19):4211-23. doi: 10.1158/0008-5472.CAN-15-1107

143. Nytko KJ, Grgic I, Bender S, Ott J, Guckenberger M, Riesterer O, et al. The Hypoxia-Activated Prodrug Evofosfamide in Combination With Multiple Regimens of Radiotherapy. Oncotarget (2017) 8(14):23702-12. doi: 10.18632 /oncotarget.15784

144. Hu J, Handisides DR, Van Valckenborgh E, De Raeve H, Menu E, Vande Broek I, et al. Targeting the Multiple Myeloma Hypoxic Niche With Th-302, a Hypoxia-Activated Prodrug. Blood (2010) 116(9):1524-7. doi: 10.1182/ blood-2010-02-269126

145. Liapis V, Labrinidis A, Zinonos I, Hay S, Ponomarev V, Panagopoulos V, et al. Hypoxia-Activated Pro-Drug Th-302 Exhibits Potent Tumor Suppressive Activity and Cooperates With Chemotherapy Against Osteosarcoma. Cancer Lett (2015) 357(1):160-9. doi: 10.1016/j.canlet.2014.11.020

146. Voissiere A, Jouberton E, Maubert E, Degoul F, Peyrode C, Chezal JM, et al. Development and Characterization of a Human Three-Dimensional Chondrosarcoma Culture for In Vitro Drug Testing. PLoS One (2017) 12 (7):e0181340. doi: 10.1371/journal.pone.0181340

147. Zhang L, Marrano P, Wu B, Kumar S, Thorner P, Baruchel S. Combined Antitumor Therapy With Metronomic Topotecan and Hypoxia-Activated Prodrug, Evofosfamide, in Neuroblastoma and Rhabdomyosarcoma Preclinical Models. Clin Cancer Res (2016) 22(11):2697-708. doi: 10.1158/ 1078-0432.CCR-15-1853

148. Stokes AM, Hart CP, Quarles CC. Hypoxia Imaging With PET Correlates With Antitumor Activity of the Hypoxia-Activated Prodrug Evofosfamide (Th-302) in Rodent Glioma Models. Tomography (2016) 2(3):229-37. doi: 10.18383/j.tom.2016.00259

149. Liapis V, Zinonos I, Labrinidis A, Hay S, Ponomarev V, Panagopoulos V, et al. Anticancer Efficacy of the Hypoxia-Activated Prodrug Evofosfamide (TH-302) in Osteolytic Breast Cancer Murine Models. Cancer Med (2016) 5 (3):534-45. doi: 10.1002/cam4.599 
150. Sun JD, Liu Q, Ahluwalia D, Ferraro DJ, Wang Y, Jung D, et al. Comparison of Hypoxia-Activated Prodrug Evofosfamide (TH-302) and Ifosfamide in Preclinical Non-Small Cell Lung Cancer Models. Cancer Biol Ther (2016) 17 (4):371-80. doi: 10.1080/15384047.2016.1139268

151. Huang Y, Tian Y, Zhao Y, Xue C, Zhan J, Liu L, et al. Efficacy of the HypoxiaActivated Prodrug Evofosfamide (TH-302) in Nasopharyngeal Carcinoma In Vitro and In Vivo. Cancer Commun (Lond) (2018) 38(1):15. doi: 10.1186/ s40880-018-0285-0

152. Portwood S, Lal D, Hsu YC, Vargas R, Johnson MK, Wetzler M, et al. Activity of the Hypoxia-Activated Prodrug, TH-302, in Preclinical Human Acute Myeloid Leukemia Models. Clin Cancer Res (2013) 19(23):6506-19. doi: 10.1158/1078-0432.CCR-13-0674

153. Meng F, Evans JW, Bhupathi D, Banica M, Lan L, Lorente G, et al. Molecular and Cellular Pharmacology of the Hypoxia-Activated Prodrug Th-302. Mol Cancer Ther (2012) 11(3):740-51. doi: 10.1158/1535-7163.MCT-11-0634

154. Sun JD, Liu Q, Wang J, Ahluwalia D, Ferraro D, Wang Y, et al. Selective Tumor Hypoxia Targeting by Hypoxia-Activated Prodrug TH-302 Inhibits Tumor Growth in Preclinical Models of Cancer. Clin Cancer Res (2012) 18 (3):758-70. doi: 10.1158/1078-0432.CCR-11-1980

155. Sun JD, Liu Q, Ahluwalia D, Li W, Meng F, Wang Y, et al. Efficacy and Safety of the Hypoxia-Activated Prodrug TH-302 in Combination With Gemcitabine and Nab-Paclitaxel in Human Tumor Xenograft Models of Pancreatic Cancer. Cancer Biol Ther (2015) 16(3):438-49. doi: 10.1080/ 15384047.2014.100300

156. Ham SL, Joshi R, Luker GD, Tavana H. Engineered Breast Cancer Cell Spheroids Reproduce Biologic Properties of Solid Tumors. Adv Healthc Mater (2016) 5(21):2788-98. doi: 10.1002/adhm.201600644

157. Liapis V, Zysk A, DeNichilo M, Zinonos I, Hay S, Panagopoulos V, et al. Anticancer Efficacy of the Hypoxia-Activated Prodrug Evofosfamide Is Enhanced in Combination With Proapoptotic Receptor Agonists Against Osteosarcoma. Cancer Med (2017) 6(9):2164-76. doi: 10.1002/cam4.1115

158. Saggar JK, Tannock IF. Chemotherapy Rescues Hypoxic Tumor Cells and Induces Their Reoxygenation and Repopulation-An Effect That is Inhibited by the Hypoxia-Activated Prodrug Th-302. Clin Cancer Res (2015) 21 (9):2107-14. doi: 10.1158/1078-0432.CCR-14-2298

159. Meng F, Bhupathi D, Sun JD, Liu Q, Ahluwalia D, Wang Y, et al. Enhancement of Hypoxia-Activated Prodrug TH-302 Anti-Tumor Activity by Chk1 Inhibition. BMC Cancer (2015) 15:422. doi: 10.1186/s12885-015-1387-6

160. Sun JD, Ahluwalia D, Liu Q, Li W, Wang Y, Meng F, et al. Combination Treatment With Hypoxia-Activated Prodrug Evofosfamide (TH-302) and mTOR Inhibitors Results in Enhanced Antitumor Efficacy in Preclinical Renal Cell Carcinoma Models. Am J Cancer Res (2015) 5(7):2139-55.

161. Wojtkowiak JW, Cornnell HC, Matsumoto S, Saito K, Takakusagi Y, Dutta P, et al. Pyruvate Sensitizes Pancreatic Tumors to Hypoxia-Activated Prodrug Th-302. Cancer Metab (2015) 3(1):2. doi: 10.1186/s40170-014-0026-Z

162. Takakusagi Y, Kishimoto S, Naz S, Matsumoto S, Saito K, Hart CP, et al. Radiotherapy Synergizes With the Hypoxia-Activated Prodrug Evofosfamide: In Vitro and In Vivo Studies. Antioxid Redox Signal (2018) 28(2):131-40. doi: 10.1089/ars.2017.7106

163. Hajj C, Russell J, Hart CP, Goodman KA, Lowery MA, Haimovitz-Friedman A, et al. A Combination of Radiation and the Hypoxia-Activated Prodrug Evofosfamide (Th-302) is Efficacious Against a Human Orthotopic Pancreatic Tumor Model. Transl Oncol (2017) 10(5):760-5. doi: 10.1016/ j.tranon.2017.06.010

164. Spiegelberg L, van Hoof SJ, Biemans R, Lieuwes NG, Marcus D, Niemans R, et al. Evofosfamide Sensitizes Esophageal Carcinomas to Radiation Without Increasing Normal Tissue Toxicity. Radiother Oncol (2019) 141:247-55. doi: 10.1016/j.radonc.2019.06.034

165. Duran R, Mirpour S, Pekurovsky V, Ganapathy-Kanniappan S, Brayton CF, Cornish TC, et al. Preclinical Benefit of Hypoxia-Activated Intra-Arterial Therapy With Evofosfamide in Liver Cancer. Clin Cancer Res (2017) 23 (2):536-48. doi: 10.1158/1078-0432.CCR-16-0725

166. Yoon C, Chang KK, Lee JH, Tap WD, Hart CP, Simon MC, et al. Multimodal Targeting of Tumor Vasculature and Cancer Stem-Like Cells in Sarcomas With VEGF-A Inhibition, HIF-1 $\alpha$ Inhibition, and Hypoxia-Activated Chemotherapy. Oncotarget (2016) 7(28):42844-58. doi: 10.18632/oncotarget

167. Kumar S, Sun JD, Zhang L, Mokhtari RB, Wu B, Meng F, et al. HypoxiaTargeting Drug Evofosfamide (Th-302) Enhances Sunitinib Activity in
Neuroblastoma Xenograft Models. Transl Oncol (2018) 11(4):911-9. doi: 10.1016/j.tranon.2018.05.004

168. Riedel RF, Meadows KL, Lee PH, Morse MA, Uronis HE, Blobe GC, et al. Phase I Study of Pazopanib Plus TH-302 in Advanced Solid Tumors. Cancer Chemother Pharmacol (2017) 79(3):611-9. doi: 10.1007/s00280-017-3256-2

169. Benito J, Ramirez MS, Millward NZ, Velez J, Harutyunyan KG, Lu H, et al. Hypoxia-Activated Prodrug Th-302 Targets Hypoxic Bone Marrow Niches in Preclinical Leukemia Models. Clin Cancer Res (2016) 22(7):1687-98. doi: 10.1158/1078-0432.CCR-14-3378

170. Lindsay D, Garvey CM, Mumenthaler SM, Foo J. Leveraging HypoxiaActivated Prodrugs to Prevent Drug Resistance in Solid Tumors. PLoS Comput Biol (2016) 12(8):e1005077. doi: 10.1371/journal.pcbi.1005077

171. Jamieson SM, Tsai P, Kondratyev MK, Budhani P, Liu A, Senzer NN, et al. Evofosfamide for the Treatment of Human Papillomavirus-Negative Head and Neck Squamous Cell Carcinoma. JCI Insight (2018) 3(16):e122204. doi: 10.1172/jci.insight.122204

172. Jayaprakash P, Ai M, Liu A, Budhani P, Bartkowiak T, Sheng J, et al. Targeted Hypoxia Reduction Restores T Cell Infiltration and Sensitizes Prostate Cancer to Immunotherapy. J Clin Invest (2018) 128(11):5137-49. doi: 10.1172/JCI96268

173. Kishimoto S, Brender JR, Chandramouli GVR, Saida Y, Yamamoto K, Mitchell JB, et al. Hypoxia-Activated Prodrug Evofosfamide Treatment in Pancreatic Ductal Adenocarcinoma Xenografts Alters the Tumor Redox Status to Potentiate Radiotherapy. Antioxid Redox Signal (2020). doi: 10.1089/ars.2020.8131

174. Weiss GJ, Infante JR, Chiorean EG, Borad MJ, Bendell JC, Molina JR, et al. Phase 1 Study of the Safety, Tolerability, and Pharmacokinetics of TH-302, a HypoxiaActivated Prodrug, in Patients With Advanced Solid Malignancies. Clin Cancer Res (2011) 17(9):2997-3004. doi: 10.1158/1078-0432.CCR-10-3425

175. Chawla SP, Cranmer LD, Van Tine BA, Reed DR, Okuno SH, Butrynski JE, et al. Phase II Study of the Safety and Antitumor Activity of the HypoxiaActivated Prodrug TH-302 in Combination With Doxorubicin in Patients With Advanced Soft Tissue Sarcoma. J Clin Oncol (2014) 32(29):3299-306. doi: 10.1200/JCO.2013.54.3660

176. Borad MJ, Reddy SG, Bahary N, Uronis HE, Sigal D, Cohn AL, et al. Randomized Phase II Trial of Gemcitabine Plus TH-302 Versus Gemcitabine in Patients With Advanced Pancreatic Cancer. J Clin Oncol (2015) 33 (13):1475-81. doi: 10.1200/JCO.2014.55.7504

177. Brenner A, Zuniga R, Sun JD, Floyd J, Hart CP, Kroll S, et al. HypoxiaActivated Evofosfamide for Treatment of Recurrent Bevacizumab-Refractory Glioblastoma: A Phase I Surgical Study. Neuro Oncol (2018) 20(9):1231-9. doi: 10.1093/neuonc/noy015

178. Laubach JP, Liu CJ, Raje NS, Yee AJ, Armand P, Schlossman RL, et al. A Phase I/Ii Study of Evofosfamide, A Hypoxia-Activated Prodrug With or Without Bortezomib in Subjects With Relapsed/Refractory Multiple Myeloma. Clin Cancer Res (2019) 25(2):478-86. doi: 10.1158/1078-0432

179. Badar T, Handisides DR, Benito JM, Richie MA, Borthakur G, Jabbour E, et al. Phase I Study of Evofosfamide, an Investigational Hypoxia-Activated Prodrug, in Patients With Advanced Leukemia. Am J Hematol (2016) 91 (8):800-5. doi: 10.1002/ajh.24415

180. Van Cutsem E, Lenz HJ, Furuse J, Tabernero J, Heinemann V, Ioka T, et al. Maestro: A Randomized, Double-Blind Phase III Study of Evofosfamide (Evo) in Combination With Gemcitabine (Gem) in Previously Untreated Patients (Pts) With Metastatic or Locally Advanced Unresectable Pancreatic Ductal Adenocarcinoma (PDAC). J Clin Oncol (2016) 34(15_suppl):4007. doi: 10.1200/JCO.2016.34.15_suppl.4007

181. Tap WD, Papai Z, Van Tine BA, Attia S, Ganjoo KN, Jones RL, et al. Doxorubicin Plus Evofosfamide Versus Doxorubicin Alone in Locally Advanced, Unresectable or Metastatic Soft-Tissue Sarcoma (TH CR-406/SARC021): An International, Multicentre, Open-Label, Randomised Phase 3 Trial. Lancet Oncol (2017) 18(8):1089-103. doi: 10.1016/S1470-2045(17)30381-9

182. Domenyuk V, Liu X, Magee D, Gatalica Z, Stark A, Kennedy P, et al. Poly-Ligand Profiling Differentiates Pancreatic Cancer Patients According to Treatment Benefit From Gemcitabine+Placebo Versus Gemcitabine+Evofosfamide and Identifies Candidate Targets. Ann Oncol (2018) 29(suppl_5):mdy151.131. doi: 10.1093/annonc/mdy151.131

183. Li Y, Zhao L, Li XF. The Hypoxia-Activated Prodrug TH-302: Exploiting Hypoxia in Cancer Therapy. Front Pharmacol (2021) 12:636892. doi: $10.3389 /$ fphar.2021.636892 
184. Anderson RF, Li D, Hunter FW. Antagonism in Effectiveness of Evofosfamide and Doxorubicin Through Intermolecular Electron Transfer. Free Radic Biol Med (2017) 113:564-70. doi: 10.1016/j.freeradbiomed.2017.10.385

185. Higgins JP, Sarapa N, Kim J, Poma E. Unexpected Pharmacokinetics of Evofosfamide Observed in Phase III MAESTRO Study. J Clin Oncol (2018) 36(15_suppl):2568. doi: 10.1200/JCO.2018.36.15_suppl.2568

186. Hunter FW, Wang J, Patel R, Hsu HL, Hickey AJ, Hay MP, et al. Homologous Recombination Repair-Dependent Cytotoxicity of the Benzotriazine Di-NOxide CEN-209: Comparison With Other Hypoxia-Activated Prodrugs. Biochem Pharmacol (2012) 83(5):574-85. doi: 10.1016/j.bcp.2011.12.005

187. Hicks KO, Siim BG, Jaiswal JK, Pruijn FB, Fraser AM, Patel R, et al. Pharmacokinetic/Pharmacodynamic Modeling Identifies SN30000 and SN29751 as Tirapazamine Analogues With Improved Tissue Penetration and Hypoxic Cell Killing in Tumors. Clin Cancer Res (2010) 16(20):4946-57. doi: 10.1158/1078-0432.CCR-10-1439

188. Mao X, McManaway S, Jaiswal JK, Patel PB, Wilson WR, Hicks KO, et al. An Agent-Based Model for Drug-Radiation Interactions in the Tumour Microenvironment: Hypoxia-Activated Prodrug SN30000 in Multicellular Tumour Spheroids. PLoS Comput Biol (2018) 14(10):e1006469. doi: 10.1371/ journal.pcbi.1006469

189. Mao X, McManaway S, Jaiswal JK, Hong CR, Wilson WR, Hicks KO. Schedule-Dependent Potentiation of Chemotherapy Drugs by the HypoxiaActivated Prodrug Sn30000. Cancer Biol Ther (2019) 20(9):1258-69. doi: 10.1080/15384047.2019.1617570

190. Chitneni SK, Bida GT, Yuan H, Palmer GM, Hay MP, Melcher T, et al. 18fEf5 PET Imaging as an Early Response Biomarker for the Hypoxia-Activated Prodrug SN30000 Combined With Radiation Treatment in a Non-Small Cell Lung Cancer Xenograft Model. J Nucl Med (2013) 54(8):1339-46. doi: 10.2967/jnumed.112.116293

191. Wang J, Foehrenbacher A, Su J, Patel R, Hay MP, Hicks KO, et al. The 2Nitroimidazole EF5 Is a Biomarker for Oxidoreductases That Activate the Bioreductive Prodrug CEN-209 Under Hypoxia. Clin Cancer Res (2012) 18 (6):1684-95. doi: 10.1158/1078-0432.CCR-11-2296

192. Grkovski M, Fanchon L, Pillarsetty NVK, Russell J, Humm JL. 18FFluoromisonidazole Predicts Evofosfamide Uptake in Pancreatic Tumor Model. EJNMMI Res (2018) 8(1):53. doi: 10.1186/s13550-018-0409-1
193. Cui YL, Wang X, Li XF. (18)F-Fluoromisonidazole PET Reveals Spatial and Temporal Heterogeneity of Hypoxia in Mouse Models of Human NonSmall-Cell Lung Cancer. Future Oncol (2015) 11(20):2841-9. doi: 10.2217/ fon. 15.205

194. Ljungkvist AS, Bussink J, Kaanders JH, Rijken PF, Begg AC, Raleigh JA, et al. Hypoxic Cell Turnover in Different Solid Tumor Lines. Int J Radiat Oncol Biol Phys (2005) 62(4):1157-68. doi: 10.1016/j.ijrobp.2005.03.049

195. Li XF, Sun X, Ma Y, Suehiro M, Zhang M, Russell J, et al. Detection of Hypoxia in Microscopic Tumors Using 131I-Labeled Iodo-Azomycin Galactopyranoside (131I-IAZGP) Digital Autoradiography. Eur J Nucl Med Mol Imaging (2010) 37(2):339-48. doi: 10.1007/s00259-009-1310-y

196. Li XF, Ma Y, Sun X, Humm JL, Ling CC, O’Donoghue JA. High 18F-FDG Uptake in Microscopic Peritoneal Tumors Requires Physiologic Hypoxia. J Nucl Med (2010) 51(4):632-8. doi: 10.2967/jnumed.109.071233

197. Huang T, Civelek AC, Zheng H, Ng CK, Duan X, Li J, et al. (18)FMisonidazole PET Imaging of Hypoxia in Micrometastases and Macroscopic Xenografts of Human Non-Small Cell Lung Cancer: A Correlation With Autoradiography and Histological Findings. Am J Nucl Med Mol Imaging (2013) 3(2):142-53.

Conflict of Interest: The authors declare that the research was conducted in the absence of any commercial or financial relationships that could be construed as a potential conflict of interest.

Publisher's Note: All claims expressed in this article are solely those of the authors and do not necessarily represent those of their affiliated organizations, or those of the publisher, the editors and the reviewers. Any product that may be evaluated in this article, or claim that may be made by its manufacturer, is not guaranteed or endorsed by the publisher.

Copyright (c) $2021 \mathrm{Li}$, Zhao and Li. This is an open-access article distributed under the terms of the Creative Commons Attribution License (CC BY). The use, distribution or reproduction in other forums is permitted, provided the original author(s) and the copyright owner(s) are credited and that the original publication in this journal is cited, in accordance with accepted academic practice. No use, distribution or reproduction is permitted which does not comply with these terms. 